\title{
High blood pressure in a semi-urban community in south-south Nigeria: a community - based study
}

\author{
*Ekanem US, Opara DC, Akwaowo CD \\ Department of Community Health, Faculty of Clinical Sciences, College of Health Sciences, University of \\ Uyo, Uyo, Akwa Ibom State, Nigeria
}

\begin{abstract}
Background: Non communicable diseases (NCDs) are taking their toll in most low and middle income countries; incidentally, in the same populations that are struggling to deal with communicable diseases, hence presenting a picture of "double tragedy". Most of the researches conducted on NCDs are facility-based; often in urban locations.

Objective: To determine the prevalence of high BP in a semi-urban community in Nigeria.

Methods: It was a cross-sectional study, where all the adult residents of the community were enrolled. Data was collected using a multi-section questionnaire, including anthropometric measurements. Data entry and analysis was done using SPSS 17.0 for windows and STATA 10.

Results: The results showed that $47.0 \%$ of the study population had a raised BP $>140 / 90 \mathrm{mmHg}$. At a univariate level, age, sex, higher income, more people in the household, daily cigarette smoking, daily alcohol intake and BMI, showed increased risk for high BP. However, sleeping for at least 8 hours a day showed protective influence against raised BP among the participants.

In the adjusted model, only age, sex and BMI remained statistically significant with Odds Ratio (OR) of 1.04 (95\%CI; 1.00 , 1.08), 0.45 (95\% CI; $0.22,0.90)$ and $1.08(95 \% \mathrm{CI} ; 1.03,1.13)$ respectively. The model had an area under curve of $71.9 \%$,

Conclusion: It was concluded that there is a high prevalence of raised BP in this semi-urban community, thus the need for intervention and preventive services to curb the looming epidemic of hypertension in this community in particular, and Nigeria as a whole, cannot be overemphasized.

Keywords: High BP, BMI, prevalence.

African Health Sciences 2013; 13(1): 56 - 61 http://dx.doi.org/10.4314/ahs.v13i1.8
\end{abstract}

\section{Introduction}

High blood pressure (BP) is a leading cause of global burden of disease, and most of it occurs in the developing world ${ }^{1}$. When selected major risk factors were assessed, the leading global risks for mortality in the world were found to be high BP (which accounted for $13 \%$ of global deaths), tobacco use $(9 \%)$, high blood glucose and physical inactivity $(6 \%$ each), overweight and obesity (5\%). These were the risk factors for developing chronic diseases such as heart disease, diabetes mellitus and cancers ${ }^{2}$.

When the burden of high blood pressure disease was further assessed, it was found that globally it accounted for 7.6 million premature deaths, 92 million DALYs ( $6 \%$ of global total), $54 \%$ stroke and $47 \%$ ischemic heart diseases. Furthermore, about $80 \%$ of disease burden caused by high BP was found to be borne by low and middle income countries,

\section{*Corresponding author:}

Dr. Uwemedimbuk S. Ekanem

Department of Community Health

Faculty of Clinical Sciences

University of Uyo, Uyo

Email: uwemedimbuk@yahoo.com by people in middle ages and those with prehypertension ${ }^{3}$. Globally, from 1980 to 2008, the number of people with uncontrolled hypertension rose from 600 million to nearly 1 billion, and overweight, obesity, high BP and high cholesterol had shifted their presence from western wealthy nations towards low and middle income countries. Regional differences showed highest systolic BP levels in Baltic, East and West African countries with higher figures for men in most regions of the world ${ }^{4}$.

In Africa, hypertension is thought to be the foundation for epidemic cardiovascular diseases ${ }^{5}$, and it had been identified as the most powerful, highly prevalent, independent, modifiable risk factor for death from heart disease and stroke at the population level ${ }^{6}$. In Soweto, approximately $46 \%$ of participants in a study had systolic/ diastolic BP values $>140$ / $90 \mathrm{mmHg}^{7}$. In the West African sub-region, hypertension prevalence rates between 1970 and 2009 in Ghana, revealed a range of $19 \%$ to $48 \%$, and in 2007, hypertension was said to be the $2^{\text {nd }}$ leading cause of outpatient morbidity in the Greater Accra region ${ }^{8,9}$. 
It is an established fact that most countries of the world are going through different phases of risk transition. Most low and middle income countries including Nigeria are in the interface between traditional and modern risk, otherwise explained as the phase of double burden of diseases, where the challenge of controlling infectious diseases have been caught up by increasing burden of noncommunicable chronic diseases ${ }^{10}$. Nigeria is not immune to the trend of global health, it is even more vulnerable considering her population growth rate and socio-economic changes, which has led to ageing populations, with dietary and lifestyle modifications, all of which tend to favour the development of non-communicable diseases. Surveillance of key modifiable risk factors is needed to monitor the magnitude of the problem of chronic noncommunicable diseases and to study the effect of interventions. This study therefore aimed at assessing the prevalence of high BP and the factors that influence BP among residents of Ibawa military barracks. The result will also serve as baseline information for evaluation of a planned intervention in the community.

\section{Methods}

It was a descriptive cross-sectional study.

The study location was $6^{\text {th }}$ battalion, Nigerian Army Barracks, Ibawa, Abak, Akwa Ibom State, Nigeria. The $6^{\text {th }}$ Battalion army barracks is a well defined community within Abak local government area. It has the administrative block (which houses all the offices), the residential quarters, a primary school, a secondary school, church, mosque and a market. The residential quarters where the army officers live with their families, are arranged in platoons. There are a total of 21 platoons in the barracks.

All eligible adults that reside at the barracks were enrolled in the study, however, pregnant women, people with obvious skeletal deformities, especially those affecting the spine and the long bones of the lower limbs, and those whose ages could not be determined were excluded from the study.

Data was collected by the researchers, six research assistants (2 Community health resident doctors and 4 Science graduates) and six community guides, some of who helped to interpret atimes. The participants were interviewed in the homes or offices, depending on where the data collectors met them.

Data collection was done using an interviewer administered semi-structured questionnaire, which was pre-tested and re-designed based on the feedback from the pre-test. It consisted of five main sections:- section A was on the socio-demographic characteristics of the participants, section B was information on the self reported health status, section $C$ was information on activity and sleep pattern, section $\mathrm{D}$ was food frequency questions, section $\mathrm{E}$ was measurements: anthropometry and blood pressure. Weight and height measurements were taken while observing standard measurement procedures ${ }^{11}$. The body mass index (BMI) was calculated using the formula, weight in kilogram divided by the square of the height in meters.

Blood pressure measurement was done using aneroid mercury sphygmomanometer, on the left mid-upper arm rested on a table, with the subject in a sitting on a chair with feet flat on the floor. Blood pressure was said to be high if two or more readings were $>140 / 90 \mathrm{mmHg}$, systolic/diastolic, at phase I and $\mathrm{V}$ Korotkoff sounds. In such cases the blood pressure was re-checked by another observer in the team, and the lowest value obtained would be recorded.

Data entry, validation and analysis were done using SPSS version 17.0 for windows and STATA 10 software. Statistical significance was decided at $\mathrm{p}$ value $<0.05$.

\section{Results}

Four hundred and forty-four people took part in the study, however two of them could not provide information on some of the socio-demographic parameters and therefore they were excluded from the analysis.

Of the 442 whose data were analysed, for some reason, measurements of some of the variables were not taken. This explains why the number " $n$ " is different for the different variables.

The socio-demographic characteristics of the participants show that they were aged 16 to 65 years with a mean age of $31.7 \pm 7.6$ years, $228(51.6 \%)$ were males and 214 (48.4\%) females. Most of them $(67.5 \%)$ had at least a secondary education. One hundred and sixteen (26.1\%) had no sources of income at all, and $95.7 \%$ of these were females. However, majority of the participants (44.6\%) earned between $\$ 30,000$ and $\$ 50,000$ per month (equivalent of $\$ 200$ and $\$ 333$ ). One hundred and eighty-one (approximately 41\%) of the participants had a maximum of two children, and $45.6 \%$ had a maximum total of 4 people in their household. 
The males were older, had more abdominal fat and

higher BP, both systolic and diastolic (table 1).

Table 1: Some characteristics of the study population

\begin{tabular}{|c|c|c|c|c|c|c|c|}
\hline \multirow[t]{2}{*}{ Variable } & \multicolumn{2}{|c|}{ Male } & \multicolumn{2}{|c|}{ Female } & \multicolumn{2}{|c|}{ Total } & \multirow[t]{2}{*}{ p-value on difference } \\
\hline & No. & Mean (sd) & No. & Mean (sd) & No. & Mean (sd) & \\
\hline Age & 228 & $34.33(7.62)$ & 214 & $28.94(6.58)$ & 442 & $31.72(7.62)$ & $<0.001$ \\
\hline BMI & 219 & $26.03(3.78)$ & 210 & $26.10(5.82)$ & 429 & $26.06(4.88)$ & 0.88 \\
\hline Abd. girth & 220 & $90.28(9.44)$ & 201 & $87.97(12.87)$ & 421 & $89.18(11.26)$ & 0.04 \\
\hline SBP & 219 & $134.38(17.11)$ & 209 & $123.60(18.71)$ & 428 & $129.12(18.62)$ & $<0.001$ \\
\hline DBP & 219 & $87.56(12.19)$ & 209 & $80.69(13.03)$ & 428 & $84.21(13.06)$ & $<0.001$ \\
\hline
\end{tabular}

$\mathrm{Sd}=$ standard deviation Abd.girth $=$ abdominal girth

Only $200(46.6 \%)$ had normal BMIs, out of these, $103(24 \%)$ were females, $X^{2}=17.36 \mathrm{p}=0.001$

Only 200 (46.6\%) had normal BMIs, out of these, 103(24\%) were females, $\mathrm{X}^{2}=17.36, \mathrm{p}=0.001$ (table 2). Forty seven percent of the study population had high BP. Difference between the sexes was statistically significant. $\mathrm{X}^{2}=25.68, \mathrm{p}<0.001$ (table 3). There was consistently increased BP; both systolic and diastolic, with increase in age, except for those aged $>60$ years. However, there was only one participant in this category (table 4).

Table 2: Distribution of participants according to BMI and sex $(n=429)$

\begin{tabular}{lllll}
\hline Sex & \multicolumn{3}{c}{ BMI categories } \\
\cline { 2 - 5 } & $<\mathbf{1 8 . 5}$ & $\mathbf{1 8 . 5 - 2 4 . 9 9}$ & $\mathbf{2 5 . 0 - 2 9 . 9 9}$ & $>\mathbf{3 0 . 0}$ \\
Male & $0(0 \%)$ & $97(22.6 \%)$ & $92(21.4 \%)$ & $30(7.0 \%)$ \\
Female & $5(1.2 \%)$ & $103(24.0 \%)$ & $58(13.5 \%)$ & $44(10.3 \%)$ \\
Total & $5(1.2 \%)$ & $200(46.6 \%)$ & $150(35.0) \%$ & $74(17.2 \%)$ \\
\hline
\end{tabular}

Table 3: Distribution of participants according to blood pressure and sex $(n=428)$

\begin{tabular}{lcc}
\hline & \multicolumn{2}{c}{ BP in $\mathbf{m m H g}$} \\
Sex & $<\mathbf{1 4 0 / 9 0}$ & $>\mathbf{1 4 0 / 9 0}$ \\
\hline Male & $90(21.0 \%)$ & $129(30.1 \%)$ \\
Female & $137(32.0 \%)$ & $72(16.8 \%)$ \\
Total & $227(53.0 \%)$ & $201(47.0 \%)$ \\
\hline
\end{tabular}

Forty-seven percent of the study population had high BP

Table 4: Distribution of participants according to mean blood pressure and age group

\begin{tabular}{lllc}
\hline $\begin{array}{l}\text { Age group in } \\
\text { years }\end{array}$ & No. & $\begin{array}{l}\text { Mean systolic BP } \\
\pm \text { SD }\end{array}$ & $\begin{array}{l}\text { Mean diastolic BP } \\
\pm \text { SD }\end{array}$ \\
\hline$<20$ & 3 & $107 \pm 6$ & $70 \pm 0$ \\
$20-30$ & 224 & $125 \pm 16$ & $81 \pm 12$ \\
$31-40$ & 148 & $130 \pm 18$ & $85 \pm 11$ \\
$41-50$ & 44 & $143 \pm 23$ & $93 \pm 14$ \\
$51-60$ & 6 & $162 \pm 22$ & $106 \pm 12$ \\
$>60$ & 1 & 140 & 90 \\
\hline
\end{tabular}

Table 4 shows that both systolic and diastolic BP increased with increase in age from $<20$ years up to 60 years of age. 
At a univariate level, for every one year increase in age there appeared to be an increased risk of high BP of $8 \%,(5-11 \%$ at $95 \% \mathrm{CI})$, male sex had an OR of 0.38 for having high BP compared to females, income appeared to have a negligible influence, but the greater the number of people in the household the higher the risk of high BP. For every $\mathrm{kg} / \mathrm{m}^{2}$ increase in BMI, there is $9 \%$ increased risk of having high BP (table 5).

In the multivariate analysis, after adjusting for cigarette smoking, alcohol intake and participants' total income, only age, sex and BMI remained as statistically significant predictive factors that influenced high BP with OR: 1.04, 0.45 and 1.08 respectively (table 6 ). The model had an area under the Receiver Operative Characteristic Curve of 0.719 .

Table 5: Univariate regression analysis of risk factors for high BP

\begin{tabular}{lllc}
\hline High BP & OR & $\mathbf{9 5 \%} \mathbf{C I}$ & $\mathbf{p}$ \\
\hline Age & 1.0831 & $1.05,1.11$ & $<0.001$ \\
Female Sex & 0.3761 & $0.25,0.55$ & $<0.001$ \\
Income & 1 & $1.00,1.00$ & $<0.001$ \\
No. in house & 1.1017 & $1.00,1.21$ & 0.04 \\
Religion & 0.6657 & $0.44,1.00$ & 0.05 \\
Atleast 8 hours of sleep & 0.3767 & $0.15,0.95$ & 0.04 \\
BMI & 1.0946 & $1.05,1.14$ & $<0.001$ \\
Daily Cigarette smoking & 2.3992 & $1.24,4.62$ & 0.01 \\
Daily alcohol intake & 3.5559 & $1.45,8.71$ & 0.01 \\
\hline OR-Ords
\end{tabular}

OR=Odds ratio

Table 6: Multivariate (adjusted model) regression for risk factors for high $\mathrm{BP}$

\begin{tabular}{lllc}
\hline High BP & OR & 95\%CI & p \\
\hline Age & 1.0428 & $1.00,1.08$ & 0.030 \\
Sex & 0.4475 & $0.22,0.90$ & 0.025 \\
income & 1.0000 & $1.00,1.00$ & 0.349 \\
No. in house & 1.0646 & $0.94,1.21$ & 0.344 \\
Religion & 0.7769 & $0.48,1.26$ & 0.304 \\
Hours of exercise & 0.9359 & $0.78,1.13$ & 0.488 \\
Hours of sleep & 0.8546 & $0.66,1.10$ & 0.226 \\
BMI & 1.0808 & $1.03,1.13$ & 0.001 \\
Cigarette & 0.9684 & $0.90,1.05$ & 0.420 \\
Alcohol & 0.9667 & $0.90,1.04$ & 0.365 \\
\hline
\end{tabular}

At multivariate level, age, sex and BMI remained statistically significant predictors of high BP.

\section{Discussion}

For over four decades now, several researchers have studied blood pressure pattern of different populations in different countries of the world, initially using the cut-off of $160 / 95 \mathrm{mmHg}$ to decide on hypertension, but currently by adopting the 140/ $90 \mathrm{mmHg}$ cut-off. It is expected that the prevalence of high BP that were observed with the 160/ $95 \mathrm{mmHg}$ cut-off would be higher if the current $140 / 90 \mathrm{mmHg}$ cut-off were to be adopted ${ }^{11}$.

\section{Prevalence of high BP}

The prevalence of high BP in this study was $47 \%$, this is slightly higher than the $42.2 \%$ observed among a market population in Enugu in $2006^{12}$, but obviously very much higher than the $18.4 \%$ and $28.2 \%$ reported from facility based studies of the prevalence of hypertension among medical admissions at UNTH, Enugu ${ }^{13}$, and UPTH Port Harcourt $^{14}$ respectively. Even in a semi-urban community in South -Western zone of the country ${ }^{15}$, a lower prevalence $(36.6 \%)$ was observed. Several other studies have recorded lower prevalence rates of high BP in Nigeria, ${ }^{16-22}$ other West African countries ${ }^{23,24}$ and even East Africa ${ }^{25}$. However, in a facility based study in south west Nigeria, $50.5 \%$ of the adults who attended the health facility were found to have high $\mathrm{BP}^{26}$, also economically developed countries have documented prevalence as high as $50 \%{ }^{27}$, and $49.4 \%$ of residents in a rural community in Spain had high $\mathrm{BP}^{25}$. The high prevalence of high BP noticed in this study is a reflection of the increasing prevalence of hypertension that is occurring in all regions of the world. In addition, the fact that some of the earlier studies referenced used the 160/95 mmHg cut off, and reported figures were extrapolations from the observed prevalence, explains the difference observed. Furthermore, the high prevalence of overweight/ obesity $(52.2 \%)$ in this study may explain partly the high prevalence of high $\mathrm{BP}$ in this population. It is an established fact that obesity is directly related to hypertension; a similar observation was made by Ulasi et al ${ }^{12}$ and Maher et a $2^{25}$. However, it may be difficult to compare the findings of different studies, as the definitions and characteristics of settings differ between studies.

\section{Predictors of high BP}

The findings from this study showed that BP increased with increase in age. A univariate analysis showed that for every year increase in age, there was 
an increased risk of high $\mathrm{BP}$ to the tune of $8 \%$, $\mathrm{p}<0.001$. The risk was however reduced at a multivariate adjusted level to $4 \%, p=0.03$ (Tables 4 $\& 5)$. This finding is similar to the finding of several other studies in Nigeria ${ }^{15,17,18} \mathrm{Uganda}^{25}$ and Ashanti, Ghana $^{29}$.

Sex was seen as one of the predictors of high $\mathrm{BP}$ in this study, with the male sex having an odds ratio of $0.45(\mathrm{p}=0.03)$ at the multivariate level; $30.2 \%$ males versus $16.8 \%$ females $(p<0.001)$ had high BP in the study. There has been conflicting reports on the association between sex and BP, but review of several articles generally show that men have higher BP than women in most regions of the world ${ }^{4}$. The finding of this study is corroborated by the findings of most other studies conducted in Nigeria ${ }^{12,15-19}$. However, while some studies in Ghana showed no gender difference 23, 24, 29, in the USA, the prevalence of high BP was higher in females ${ }^{27}$ and worldwide data as at 2003 revealed that prevalence of hypertension was lowest (3.4\%) among rural Indian men and highest $(72.5 \%)$ among Polish women ${ }^{30}$. The fact that the men in the present study were older; mean age $34.3 \pm 7.6$ years versus $28.9 \pm 6.6$ years in females $(\mathrm{p}<0.001)$, and more overweight/obese; $28.4 \%$ versus $23.8 \%$ of females $(\mathrm{p}=0.001)$, explains why more men had high BP in the study.

Apart from age and sex, BMI was also observed as a predictor of BP from the data. The prevalence of overweight and obesity in this study was $52.2 \%$; overweight $35 \%$, obesity $17.2 \%$. The obesity prevalence of $17.2 \%$ is lower than the $19.2 \%$ and $22.6 \%$ observed by Ulasi et al in a semi-urban community and among market workers respectively ${ }^{12}$. However, the data showed that BMI is a positive predictor of high BP, OR 1.08, (CI 1.03, 1.13. $\mathrm{p}=0.001$, which is similar to the finding from several other studies ${ }^{12,16,17,25,26}$. S e v e r a l other factors such as cigarette smoking, poor diets (eating of unhealthy/salt-laden diets) and physical inactivity (sedentary lifestyle) have been reported as contributors to high $\mathrm{BP}{ }^{12}$, but the present study did not establish the relationship between these factors and high BP. It was surprising to note that cigarette smoking was a statistically significant predictor of high $\mathrm{BP}$ at the univariate level only. Also, it is not clear if the availability of social amenities in the barracks; electricity and borehole water, may have encouraged the residents to spend hours watching films and TV, leading to relatively sedentary lifestyle, and thus increase in BP; or to what extent their BP at recruitment could have contributed to the observed
BPs, noting that it has been documented that that even among army recruits, high $\mathrm{BP}$ was seen as the commonest condition ${ }^{28}$. Further epidemiological research will be required to confirm or refute such associations in this population. In conclusion, the prevalence of high $\mathrm{BP}$ in this semi-urban community is quite high $(47 \%)$, the predictive factors were age, sex and BMI. This implies that there is an impending epidemic of cardiovascular diseases in this community, hence the need to develop health delivery tools for early identification and prompt treatment of hypertension. Additionally, public health measures to combat the growing risks should be instituted. Lifestyle modification in addition to treatment have been proven to decrease high BP and prevent its complications, the time to act is now.

\section{References}

1. Lawes CM, Vander Hoorn S, Law MR, Elliott P, MacMahon S, Rodgers A. Blood pressure and the global burden of disease 2000. Part II: estimates of attributable burden. J Hypertens. 2006 Mar; 24(3):423-30.

2. WHO, 2009. Global health risks: mortality and burden of disease attributable to selected major risks.

3. Lawes CM, Vander Hoorn S, Rodgers A; Global burden of blood-pressure-related disease, 2001. Lancet. 2008 May 3; 371(9623):1513-8.

4. Danaei G, Finucane MM, Lin JK, et al, on behalf of the Global Burden of Metabolic Risk Factors of Chronic Diseases Collaborating Group (Blood Pressure). National, regional, and global trends in systolic blood pressure since 1980: systematic analysis of health examination surveys and epidemiological studies with 786 countryyears and 5.4 million participants. Lancet 2011; published online Feb 4. DOI: 10.1016/S01406736(10)62036-3.

5. Cooper RS, Amoah AG, Mensah GA. High blood pressure: the foundation for epidemic cardiovascular disease in African populations. Ethn Dis. 2003 summer; 13 (2 Suppl 2):S48-52.

6. Kannel WB, Wolf PA, Verter J et al. Epidemiologic assessment of the role of blood pressure in stroke. The Framinghan study. JAMA 1970; 214: 301-10.

7. Maseko MJ, Norton GR, Majane OH, Molebatsi $\mathrm{N}$, Woodiwiss AJ. Global cardiovascular risk profiles of untreated hypertensives in an urban, developing community in Africa. Cardiovasc J Afr. 2010 Dec 15;21:1-7. 
8. Bosu WK. Epidemic of hypertension in Ghana: a systematic review. BMC Public Health. $2010 \mathrm{Jul}$ 14;10:418. Doi: 10.1186/1471-2458-10-418

9. Greater Accra regional Health Directorate. Annual Report 2007. Accra: Ghana Health Service; 2008.

10. Alan DL, Colin DM, Majid E, Dea TJ, Christopher JM. Global burden of disease and risk factors. Oxford University Press and the World Bank. Chapter 1: Page 3.

11. The Seventh Report of the Joint National Committee on Prevention, Detection, Evaluation and Treatment of High Blood Pressure (The JNC 7 Report) JAMA 2003; 289 (19): 2560-72.

12. Ulasi II, Ijoma CK, Onwubere BJ, Arodiwe E, Onodugo O, Okafor C. High Prevalence and Low Awareness of Hypertension in a Market Population in Enugu, Nigeria. International Journal of Hypertension, 2011, Article ID 869675, 5 pages. doi: $10.4061 / 2011 / 869675$

13. Ike SO. Prevalence of hypertension and its complications among medical admissions at the University of Nigeria Teaching Hospital, Enugu (study 2). Niger J Med. 2009;18(1):68-72.

14. Onwuchekwa AC, Chineye S. Clinical profile of hypertension at a University Teaching Hospital in Nigeria. Vasc Health Risk Manag. 2010;9 (6):5116.

15. Rufus AA, Chidozie EM, Michael OB, Tanimola M, Rasaaq AA, Anthony A, Patience OA. Prevalence and pattern of hypertension in a semiurban community in Nigeria. Eur. J. Cardiovasc. Prev Rehabil. 2008;15:683-687.

16. Clareann HB, Flora AU, Martin UN, Jackson AO, Glenn WC, Linda HK.et al. Factors associated with hypertension in Nigerian civil servants. Preventive Medicine, 1992;21(6): 710-22.

17. Oghagbon EK, Okesina AB, Biliaminu SA. Prevalence of hypertension and associated variables in paid workers in Ilorin, Nigeria. Nig. J. of Cl. Practice; 2008(11): 4; 342-6

18. Obinna IE, Patrick OU, Izuchukwu LN. Prevalence, awareness, treatment and control of hypertension in a Nigerian population. DOI:10.4236/health.2010.27111.

19. Olatunbosun ST, Kaufunan JS, Cooper RS, Bella AF. Hypertension in a black population: prevalence and biosocial determinants of high $\mathrm{BP}$ in a group of urban Nigerians. Journal of Human Hypertension. 2000; 14(4): 249-57.
20. Non-Communicable Diseases (NCD) in Nigeria - final report of a national survey Federal Ministry of Health - National Expert Committee on NCD; 1997.

21. Lawoyin TO, Asuzu MC, Kaufman J, et al.: Prevalence of cardiovascular risk factors in an African urban, inner city community. West Afr J Med 2002, 21:208-211.

22. Kadiri S, Walker O, Salako BL, Akinkugbe OO: Blood pressure, hypertension and correlates in urbanized workers in Ibadan, Nigeria - a revisit. J Hum Hypertens 1999 , 13:23-27.

23. Amoah AB. Hypertension in Ghana: a crosssectional community prevalence study in Greater Accra. Ethn Dis. 2003; 13: 310-315.

24. Cooper R, Rotimi C, Ataman S, McGee D, Osotmehin B, Kadiri S, Muna W, Kingue S, Fraser H, Forrester T, Bennett F, Wilks R. The prevalence of hypertension in seven populations of West African origin. Am J Public Health. 1997; 87: 160168.

25. Maher D, Waswa L, Baisley K, Karabarinde A, Unwin N. Epidemiology of hypertension in lowincome countries: a cross sectional populationbased survey in rural Uganda. DOI:10.1097/ HJH.Ob 013e 3283466e90.

26. Amole IO. Olaolorun AD, Odeigah LO, Adesina SA. The prevalence of abdominal obesity and hypertension among adults in Ogbomoso, Nigeria. Afr. J. Prim Health care Fam. Med. 2011;3(1), Art 188, 5pages. DOI:10.4102/ phcfm.v3; 188.

27. Hall WD, Ferrario CM, Moore MA, Hall JE, Flack JM, Cooper W, et al. hypertension-related morbidity and mortality in the southeastern United States. Am J Med Sci. 1997; 313(4):195-209.

28. Awoyemi AO,Osagbemi GK, Ogunleye VA. Medical examination findings among army recruits in Ilorin. West Afr J Med 2001; 20(3): 2568.

29. Francesco P. Cappuccio; Frank B. Micah; Lynsey Emmett; Sally M. Kerry; Samson Antwi; Ruby Martin-Peprah; Richard O. Phillips; Jacob PlangeRhule; John B. Eastwood .Prevalence, Detection, Management, and Control of Hypertension in Ashanti, West Africa. Hypertension. 2004; 43:10171022

30. Kearney PM, Whelton M, Reynolds K, Whellton PK, He J. Worldwide prevalence of hypertension: a systematic review. J Hypertens. 2004; 22:11-19. 